\title{
PRESENTACIÓN DE LA REVISTA
}

Tengo la satisfacción de presentar el cuarto número de la Revista de Derecho. Escuela de Postgrado, publicación periódica de la Facultad de Derecho de la Universidad de Chile, que busca contribuir al compromiso con la investigación y la excelencia académica de nuestra Universidad.

En la sección correspondiente a Doctrina, se incluyen cinco artículos. En el primero, "La responsabilidad civil por actividades peligrosas: aplique primero y explique después", los profesores Dr. Carlos Pizarro y Fabricio Mantilla nos señalan que la interpretación del artículo 2329 del Código Civil chileno tiene una historia compleja, que ha sido objeto de diversas interpretaciones, oscilando entre quienes entienden dicha regla como presunción de culpa o responsabilidad objetiva o una simple iteración del principio de responsabilidad por culpa. Su análisis desde la perspectiva del derecho comparado chileno y colombiano, nos permite concluir que es inexacto afirmar la existencia de un régimen por culpa presunta en el caso colombiano, el que debe reconocerse como un régimen objetivo. En cambio, en el caso chileno, el dilema está en acoger la presunción de culpa o rechazarla.

El Dr. Jonatan Valenzuela Saldías, en su artículo "Ciudadania transnacionaly derecho penal: a propósito del caso europeo", analiza el marco político de comprensión de la ciudadanía, que se ve intensamente puesto a prueba por los intentos de construcción de espacios de deliberación transnacionales. Esta tensión tiene un aspecto de relevancia frente a la justificación filosófico política del derecho penal: el reconocimiento y las expectativas políticas determinan la forma que el derecho penal ha de tener en el contexto de estos nuevos espacios de deliberación.

Mauricio Hormazábal Valdés, en "Problemas actuales en la aplicación de la multa laboral', realiza un análisis legal y constitucional sobre la juridicidad de la aplicación de multas laborales que realiza la Inspección del Trabajo. Bajo el prisma de las categorías dogmáticas constitutivas del Derecho Administrativo sancionador, se denuncia el bajo estándar jurídico de las actuaciones de tal agencia en nuestro Estado de Derecho, particularmente frente a los principios de legalidad, tipicidad, responsabilidad y debido proceso, reconocidos por nuestros Tribunales, teniéndose presentes diversos fallos del Tribunal Constitucional.

Pablo Aranda Valenzuela, en su artículo "Los derechos de aprovechamiento de aguas en Chile y su marco regulatorio", analiza la administración del recurso hídrico en Chile a través del mercado. El autor realiza una descripción del sistema regulatorio en materia hídrica a partir del Código de Aguas de 1981 a la fecha, refiriéndose a las potestades de la agencia asignadora del agua. Asimismo, reflexiona acerca de las fallas que presenta el sistema de mercado en la asignación de las aguas 
y las características peculiares de las asignaciones. Concluye postulando propuestas para un mejor funcionamiento del sistema hídrico, tendientes a una eficiente utilización del recurso.

La Dra. Miriam Henríquez Viñas en su artículo "El control de constitucionalidad de los Decretos con Fuerza de Ley", trata sobre la competencia del Tribunal Constitucional para ejercer el control de constitucionalidad de los decretos con fuerza de ley. Particularmente, analiza si las Cámaras o una cuarta parte de sus miembros pueden recurrir al Tribunal Constitucional para impugnar el decreto con fuerza de ley vigente cuando excede o contraviene la ley delegatoria y si este supuesto implica un vicio de legalidad o de constitucionalidad.

Joaquín Recart Apfelbeck en su artículo "El impeachment estadounidense y su influencia sobre la acusación constitucional chilena", realiza un interesante análisis histórico sobre el origen del impeachment estadounidense y la manera en que este influyó sobre la regulación de la acusación constitucional en Chile, particularmente en aspectos como la elección de los órganos que intervienen en él, las causales por las cuales una autoridad puede ser acusada y el alcance de la sanción que afecta a la autoridad.

La sección de Documentos comprende un adelanto del libro "Historia de dos demandas: Perú y Bolivia contra Chile”, del Director del Programa de Relaciones Internacionales de nuestra Facultad, profesor José Rodríguez Elizondo, titulado "Apuntes en vísperas del fallo de La Haya". Además se incluye un análisis del ex presidente de la Corte Suprema, Urbano Marín Vallejo: “jJudicialización de la política y politización de la justicia?”. Finalmente, la Decano de la Facultad de Derecho de la Universidad Autónoma de México (UNAM), Dra. María Leoba Castañeda Rivas, escribe "De la ética a la ley, el inevitable o evitable peso de la reacción social formal en el ámbito civil. El Caso de la Legislación en el Distrito Federal'.

En la sección Comentario de Jurisprudencia se incluyen el trabajo de la profesora del McGeorge School of Law de la Universidad del Pacífico de California, Dra. Julie Davies, sobre "Sentencias Trascendentales del Tribunal Supremo de los Estados Unidos. Pasos hacia la igualdad del matrimonio para parejas del mismo sexo"; y el de los profesores José Francisco García y Sergio Verdugo "De los derechos políticos a las listas de lavandería. Los problemas del caso 'Cruz-Coke".

En la sección Análisis Legislativo, el Director del Departamento de Derecho Privado de nuestra Facultad, profesor Mauricio Tapia Rodríguez realiza "Comentarios al Proyecto de Nuevo Código Procesal Civil’. Por su parte, el Director del Servicio Nacional del Consumidor, Juan José Ossa Santa Cruz, y Luis Álvarez Estay analizan "La etapa de admisibilidad de las acciones para la defensa del interés colectivo y difuso de los consumidores". Se incluyen también mis "Comentarios al Boletín $N^{\circ}$ 9119-18 Reforma integral al sistema de adopción en Chile"; e Ignacio Araya y el profesor Octavio Bofill realizan un "Análisis y comentarios a la reforma al Régimen Concursal (Boletín No 8324-03)”. 
Finalmente, quiero agradecer al profesor Cristián Lepin Molina, Subdirector de la Revista, a Karen Muñoz Villagra, Editora General de la Revista, y a los miembros del Comité de Redacción, Sergio Cortés Beltrán y Marcela Ruiz Calderón, por su trabajo de edición en este número.

\author{
Dra. Maricruz Gómez de la Torre Vargas \\ DiRECTORA \\ ReVista de Derecho \\ Escuela de Postgrado
}

